\title{
Ict Integration As A Source Of Learning In Primary Schools Education: Analysis Between Potential And Reality
}

\author{
$1^{\text {st }}$ Muhammad Ragil Kurniawan ${ }^{1}, 2^{\text {nd }}$ Nurul Hidayati Rofiah ${ }^{2}$ \\ \{ragil.kurniawan@pgsd.uad.ac.id ${ }^{1}$, nurul.rofiah@pgsd.uad.ac.id²
}

Universitas Ahmad Dahlan Yogyakarta Indonesia ${ }^{1,2}$

\begin{abstract}
The industrial revolution 4.0 brought impacts on all aspects of life, including education. In the field of education, there needs to be a concurrent reflection on the application of ICT as part of learning activities. The purposes of this script are: 1) to analyze the potential use of ICT in learning in elementary schools. 2) Knowing the typology of the use of IT in primary schools in the City of Yogyakarta. The analysis uses a classification issued by UNESCO. The results are a) Potential utilization of ICT in elementary school learning should have used ICT for learning (integrating and transforming). b) mapping some patterns of computer laboratory use in elementary schools in the city of Yogyakarta said the majority of schools (more than $80 \%$ ) still use computer laboratories on aspects of how to using ICT, and just a few schools use ICT to learning.
\end{abstract}

Keywords: Education, ICT, Learning, Schools

\section{Introduction}

The industrial revolution 4.0 has truly become a socio-cultural pattern of society. Integration of information-technology and internet technology in various aspects of life can really be felt the impact of efficiency and effectiveness. Online transportation is one example of the strong impact of the 4.0 industrial revolution in the transportation sector. The community can really feel the conveniences of the implementation of information-technology and internet integration in this aspect of transportation in various aspects. Online ticket reservations (especially planes and trains), order taxis and motorcycle taxis online, to order online meals are examples of the progress of efficiency and effectiveness in the field of transportation that is felt by the community.

The condition of the rise of online culture indicates that the community does not only have the application and technology that it has. However, this condition has indicated that socio-cultural and patterns of life of the people have changed. Socio-cultural changes in society have actually touched on all aspects of life, not inseparable in aspects of education. Education is also feasible for self-evaluation, how it should be effective and efficient education with modern facilities and socio-cultural patterns of society that are no longer the same as 10 years ago.

Education as one aspect of the development of human potential needs to change the mindset of its implementation from time-based learning to being outcome-based learning (learning that is truly oriented towards increasing the competencies of students) (Anderson: 2010). Learning that used to be passive learning 
namely, students just sit quietly listening to the explanation from the teacher, become active learning, namely students who actively find knowledge from their various activities in school. This condition also ideally shifts the paradigm which previously positioned the teacher as the main learning source, now it is not the time and changing that the teacher is the facilitator who plays a role in providing and ensuring student learning facilities are available with the culture change then bringing up a device called utilization ICT to create student learning experiences. To follow up on the background, this study aims to: 1) analyze the potential use of ICT in learning in elementary schools. 2) knowing the typology of the use of IT in primary schools in the City of Yogyakarta.

\section{Research Methods}

This study uses two methodologies. At the beginning is using the discourse analysis method to find the analysis method that will be used to analyze the data. After the analytical knife theory framework was found, further field research was conducted using survey methods with samples of more than $10 \%$ of the population. The population in this study was an elementary school in the city of Yogyakarta.

Data on the use of ICT in learning is limited to the use of ICT in a systematic and structured manner by schools, not limited to individual teacher initiatives. In order to maintain the validity of the data in this study, then one form of limiting the use of ICT systematically and structured by schools is to map the use of computer laboratories by schools. In addition, opportunities for ICT utilization are smartphone use while at school. Therefore these two main data were explored in this study.

\section{Discussion}

\subsection{Utilization of ICT for learning: a theoretical analysis}

Referring to the identification carried out by Anderson and van Weert (2002), Majundar (2005) in their work with UNESCO, there are four levels of ICT usage in the educational realm. The four levels are: emerging, applying, infusing and, transforming (figure 1). These four levels are the integration between pedagogy and technology. Pedagogy represents the development of learning practices that lead to studentcentered learning while technology represents the development of ICT utilization in an educational context (ADB, 2017). These four levels can be used by education stakeholders in mapping the quality of learning, especially the use of technology in improving the competency of students as a whole, and not merely how technology is used.

The emerging stage is the beginning point of ICT in the education process. At this stage, with limited ICT tools and infrastructure in most schools, teachers are expected to master the basic ICT tools and available ICT-enabled resources and applications for their teaching, learning, and administrative tasks. ICT-enabled teaching practices are generally teacher-centered. The following are the limits of the four levels according to the Asian Development Bank (2017).

At the applying stage, with the support of the national ICT policies and a variety of ICT in education initiatives and strategies, there is better access to ICT infrastructure and resources (compared with the 
emerging stage) and teachers become more confident in the use of specific ICT tools to enhance the quality of their teaching. However, the enhancement in the quality of teaching is focused on teachers using the ICT tools rather than students using the ICT tools. Moreover, ICT is still often seen as a separate curriculum area for students to learn about ICT-related competencies.

At the infusing stage, teachers use ICT to enhance their own professional learning and the learning quality of their students. Teachers and students have good access to ICT infrastructure and resources. Teachers are competent in the use of ICT for enhancing the quality of student learning through a more learnercentered environment and activities. Teachers are more likely to collaborate with other teachers to develop and share ICT-enabled teaching and learning resources and practices. However, ICT is still perceived as a tool to support the existing curriculum rather than a tool to transform the curriculum.

When it comes to the transformation stage, ICT is used by teachers for most of their personal and professional tasks and activities. At this stage, teachers use different types of ICT tools to enhance teacherstudent and student-student interactions to create a learner-centered learning environment to engage students and enhance their learning outcomes. The national curriculum is designed and school ICT in education plans are developed to take up the opportunities of ICT for enhancing education equity, quality, and efficiency.

By drawing upon the holistic approach to ICT in education and the model of stages of ICT in education, the system perspective provides a framework to make sense of the state of ICT in education in Indonesia.

Referring to the seminar paper made by Chaeruman (2018), emerging and applying are included in one basic category, namely, students are still taught to use ICT (learning to use ICT). At these two levels ICT is limited as a learning object. infusing and transforming levels are included in the category of using ICT for learning (creating experiences for students). At these two levels, ICT has been utilized to create a learning environment for students (to create learning experiences).

Referring to the discussion above, schools can use ICT at the level of Infusing and Transforming. In the use of ICT in learning, teachers do not just stop at emerging and applying levels. Students are currently born in the era of ICT, so it doesn't take much time for students to learn about how to use ICT. On the contrary, what needs to be encouraged to be maximized now is how to teach students to use ICT for learning needs, not just limited to entertainment and games without educational value.

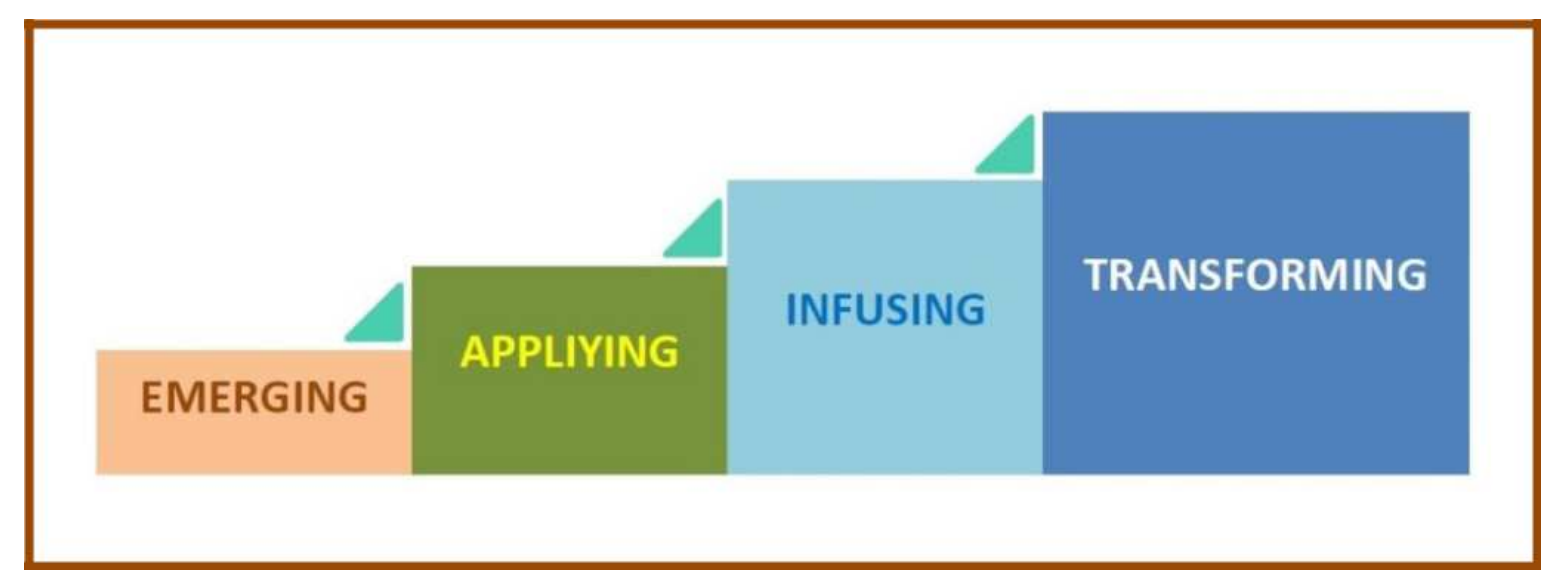

Fig 1. The level of ICT utilization according to UNESCO 
Regarding the increase in teacher competency in the use of ICT in education, there is a good example given by Miao (2013) in a discussion of UNESCO High-level Policy Forum in ICT and Education. Figure 2 below is an adoption of the example given by Miao in stages in detail increasing teacher competence in the use of ICT in learning.

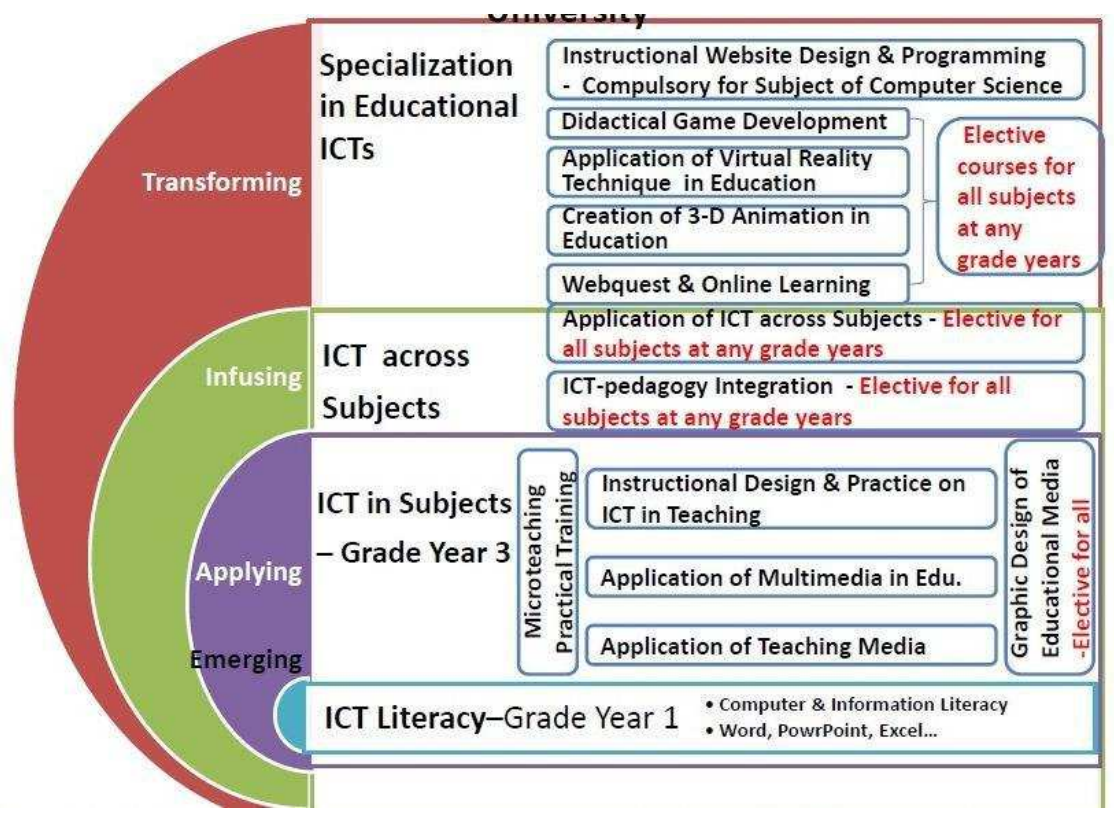

Fig 2. Enhancing teacher competence in the use of ICT in learning

Emerging levels are used to train teachers in introducing students to specific programs in learning. The applying level is more on introducing multimedia implementation for teaching. At the infusing level, you have started to train teachers to integrate ICT in learning. at this infusing level, teachers are trained to use ICT not as limited as a learning media but have begun to use ICT as a learning resource but are still separated from each other across subjects. At the level of transforming teachers are trained to use ICT truly as a source of learning for students, while teachers are facilitators of learning.

\subsection{The reality of the use of ICT in learning in elementary schools}

In the presentation of the research results, three main data were obtained. The results of the first study show that not all primary schools have computer laboratories. Only $77,78 \%$ of schools already have computer laboratories. There are still $22,22 \%$ of primary schools that do not have computer laboratories. All schools do have computers, but those included in the computer category as a laboratory are only 77.78 schools. Figure 3 below shows the visualization of ownership of a computer laboratory in elementary schools in the city of Yogyakarta. 


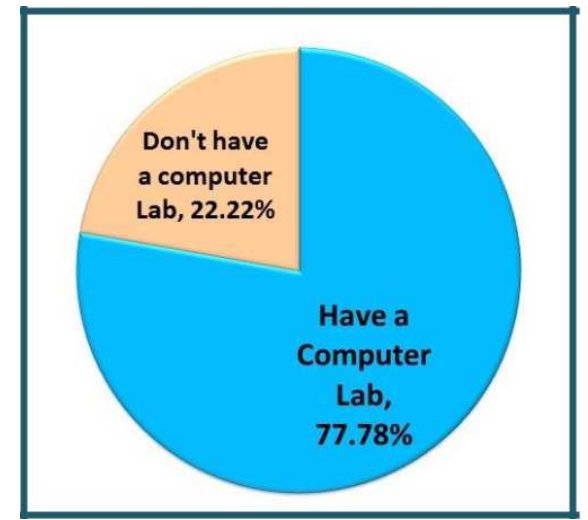

Fig 3. Ownership of Computer Laboratories in Schools

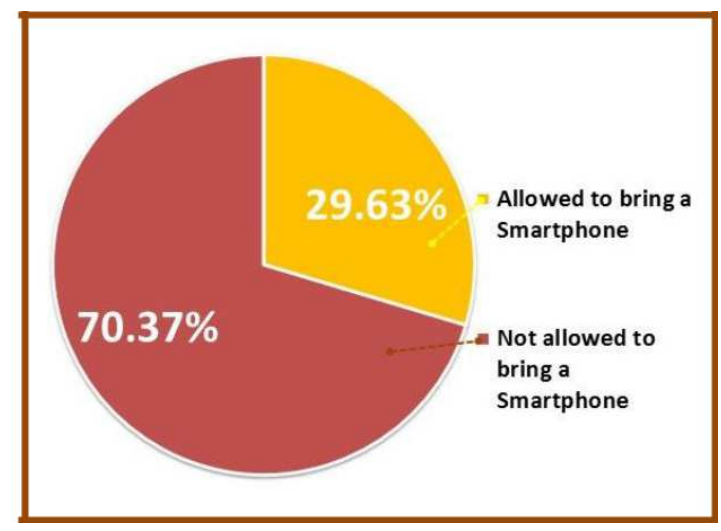

Fig 4. Allowing to bringing the smartphone to school

Ownership of computer labs is a dominant factor in the use of ICT, especially those based on cloud computing, in learning at school. This is because the majority of elementary schools still do not allow students to bring smartphones in schools, especially during learning. This conclusion emerged from the results of a second study which stated that $70,37 \%$ of schools did not allow students to take smartphones to school. Only $29,63 \%$ of school respondents allow students to take smartphones to school. From schools that allow students to bring smartphones when they go to school, the main reason is to communicate the students with the parents, and none of them officially gives reasons for learning activities.

The results of the third study are a follow up to the results of the first study. Of the approximately $78 \%$ of schools that have computer laboratories, $80.95 \%$ are used to teach extracurricular computers. In other words, $80.95 \%$ of the total schools that have computers are used to teach how to use computers or use several computer applications. While schools that have used computer laboratories for learning or to create learning environments amount to $19.05 \%$ of primary schools. Figure 5 below shows the visualization of the percentage of use of ICT for learning in school. 


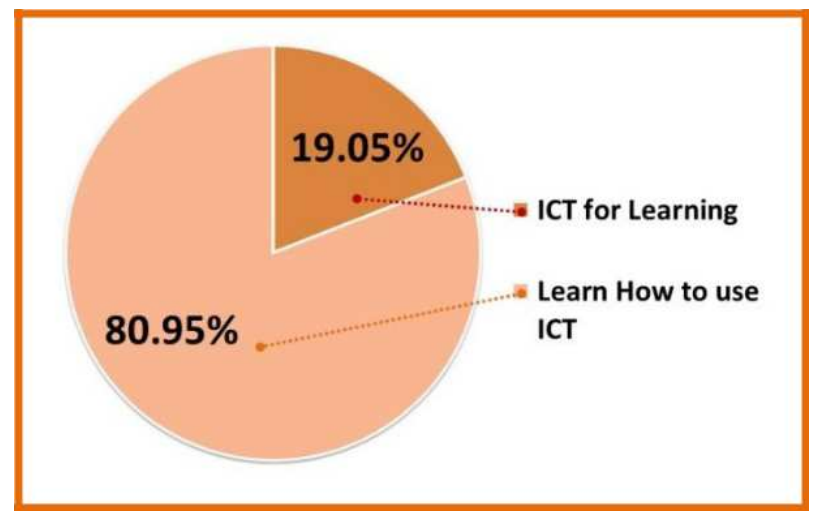

Fig 5. The level of using ICT for learning.

Mapping the use of computer use in schools in this study uses a classification developed by UNESCO (2013) which divides the use of computers into four levels. The four levels of computer use are emerging, applying, infusing and, transforming. Of the four levels, Chaeruman (2018) is classified into two in general. The emerging and applying level is in the ITC learning to use category while infusing and transforming levels are categorized as ICT for learning or ICT to create learning experiences. Using the results of the analysis as a theoretical basis, this study divides the category of ICT usage in elementary school learning, namely the first learning to use ITC and the second ICT for learning. From the research data, it can be concluded that elementary schools in Yogyakarta are still dominantly using ICT to learn about ICT (80.95\%). Not more than a quarter of schools in Yogyakarta City use ICT for learning.

\section{Conclusion}

Based on the results of the discussion two main things can be concluded: a) Potential utilization of ICT in elementary school learning should have used ICT for learning (integrating and transforming). b) mapping some patterns of computer laboratory use in elementary schools in the city of Yogyakarta said the majority of schools (more than $80 \%$ ) still use computer laboratories on aspects of how to using ICT, and just a few schools use ICT to learning.

\section{References}

[1] Anderson, Jonathan. 2010. ICT Transforming Education: a regional guide. UNESCO: Bangkok

[2] Asian Development Bank. 2017. Innovative strategies for accelerated human resources development in south Asia information and communication technology for education. ADB: Manila.

[3] J. Anderson and T. van Weert, 2002. Information and Communication Technology (ICT) in education: A Curriculum for Schools and Program of Teacher Development. Paris: Unesco. http://unesdoc.unesco.org/image/0012/001295/129538e.pdf (accessed 20 June 2019) 
[4] Chaeruman, Uwes A. 2018. 21st Century Education. Delivered on Nasional Seminar On 21st-century education, by education center Ministry of Education and Culture, Sawangan, 27 April 2018.

[5] S. Majundar, ed. 2005. Regional guidelines on Teacher Development for Pedagogy-Technology Integration. Bangkok, UNESCO Regional office for education in Asia and the Pacific.

http://unesdoc.unesco.org/image/0014/0001405/140577e.pdf

[6] Miao, Fengchun. 2013. UNESCO Strategy for ICT in Education: challenges, priority area, and deliverables.

[7] UNESCO.http://www.unesco.org/new/fileadmin/MULTIMEDIA/HQ/ED/pdf/Session5_UNESCO_ICT_in_E du_Programme_ED.pdf (accessed 02 July 2019) 
